WellBeing International

WBI Studies Repository

$1-2009$

\title{
Resources, not Kinship, Determine Social Patterning in the Territorial Gunnison's prairie Dog (Cynomys gunnisoni)
}

\author{
J. L. Verdolin \\ Stony Brook University \\ C. N. Slobodchikoff \\ Northern Arizona University
}

Follow this and additional works at: https://www.wellbeingintlstudiesrepository.org/acwp_asie

Part of the Animal Studies Commons, Behavior and Ethology Commons, and the Comparative Psychology Commons

\section{Recommended Citation}

Verdolin, J. L., \& Slobodchikoff, C. N. (2009). Resources, not kinship, determine social patterning in the territorial Gunnison's prairie dog (Cynomys gunnisoni). Ethology, 115(1), 59-69.

This material is brought to you for free and open access by WellBeing International. It has been accepted for inclusion by an authorized administrator of the WBI Studies Repository. For more information, please contact wbisr-info@wellbeingintl.org.

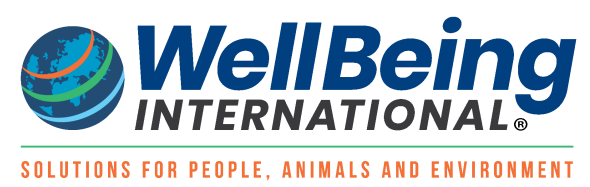




\title{
Resources, not Kinship, Determine Social Patterning in the Territorial Gunnison's prairie Dog (Cynomys gunnisoni)
}

\author{
J.L. Verdolin ${ }^{1}$ and C.N. Slobodchikoff ${ }^{2}$ \\ ${ }^{1}$ Stony Brook University \\ ${ }^{2}$ Northern Arizona University
}

\begin{abstract}
In this study, we describe patterns of relatedness in Gunnison's prairie dog (Cynomys gunnisoni) social groups. Kin selection is often cited as a mechanism for the evolution and maintenance of social groups, and Gunnison's prairie dog females are occasionally described as being strongly philopatric. Overall, randomization tests revealed that females within territorial groups were not more closely related to each other than expected at random. A similar pattern was found among males and between males and females, indicating that there was no sex-biased dispersal occurring in these populations. Ecological variables measured in this study, such as food abundance and food dispersion, were not correlated with relatedness. In addition, territory size and density $/ \mathrm{m}^{2}$ did not correlate significantly with relatedness. Although there was variability in the spatial overlap among individuals within groups, there was no indication that relatedness explained this variation. These results suggest that kin selection is not maintaining social groups in these populations, but that competition for access to resources required by both males and females may explain dispersal and social group patterns in these populations.
\end{abstract}

\section{Introduction}

A central theme of behavioral ecology lies in understanding the evolution and maintenance of animal grouping patterns and cooperation. Because living in groups can carry significant reproductive costs (e.g., reduced resource acquisition, increased infanticide, and reproductive suppression), individuals living in groups must experience fitness benefits that exceed the actual fitness costs of sociality (Alexander 1974; Betram 1978; Wasser \& Barash 1983; Wrangham \& Rubenstein 1986; Janson 1992; Emlen 1997; Solomon \& French 1997; Armitage 2003).

Kinship structure can have a profound influence on the degree and nature of social interactions by affecting the level of cooperation (Hamilton 1964a,b), dispersal, inbreeding avoidance (Shields 1982) and the degree of reproductive skew (Vehrencamp 1983). Although genetic relatedness is not a prerequisite for social groups, kinship may influence the degree of aggression during periods of environmental stress and membership status in a group (Giraldeau \& Caraco 2000). Though there is some evidence that as relatedness increases aggression decreases, both within the group and with neighboring related groups (Brown \& Brown 1993; Reeve \& Nonacs 1997), more recent empirical investigations suggest that 
increased competition and aggression among relatives may reduce or eliminate kin-selected benefits (West et al. 2001; Griffin \& West 2002). Kin-related groups may also determine when and which other individuals join a group, thereby regulating group size (Giraldeau \& Caraco 2000).

The connection between cooperation and kinship was first proposed by Hamilton (1964a,b). Hamilton proposed that the costs and benefits of social interactions are mediated by inclusive fitness through close genetic relatedness. Recently, it has been suggested that high amounts of cooperation within groups may be favored by factors in addition to kin selection (Slobodchikoff 1984; Slobodchikoff \& Schultz 1988; Clutton-Brock 2002). For instance, when dispersal is limited and juveniles cannot locate suitable mates, relatedness within groups may be higher (Dugatkin 1997). For many birds and mammals retention of young in the natal group (philopatry) is common and believed to provide the foundation for the evolution of sociality and lead to the formation of kin-structured groups (Hatchwell \& Komdeur 2000). The two primary hypotheses explaining natal philopatry are the 'ecological constraints hypothesis' (Emlen 1984) and the 'benefits of philopatry hypothesis' (Stacey \& Ligon 1987, 1991). Both hypotheses postulate costs and benefits of staying vs. dispersing. Dispersing often can carry significant costs that result in lower survival rates (Daniels \& Walters 2000). However, not dispersing can lead to increased within-group competition via foraging interference, reproductive suppression, reduced access to mates and increased aggression (Wasser \& Barash 1983; Janson 1988; Solomon \& French 1997; West et al. 2002; Griffin \& West 2002; Armitage 2003). Thus, balancing costs and benefits, individuals may disperse to improve the quality of their reproductive success or, as population density increases, individuals may disperse to reduce their intraspecific competition within a territory.

Frequently, dispersal decisions are sex-biased, with either males or females remaining in the natal territory. According to Greenwood (1980), dispersal is linked to mating systems (e.g., resource based) and whichever sex competes for resources should be philopatric. While in some species the occurrence of philopatry may be correlated with the mating system, recent experimental studies suggest that the frequency of philopatry may instead depend on the population density and the availability of food resources and their predictability in space and time (Emlen 1982, 1995; Koenig et al. 1992; Johnson et al. 2002). This pattern suggests that parent-offspring conflicts over food resources may influence how much dispersal occurs, leading to varying degrees of relatedness among individuals in a social unit (Waser \& Jones 1983). In carrion crows (Corvus corone), for example, increases in food abundance increased the retention of offspring, suggesting that when times are good, dispersal from the natal territory may be reduced (Baglione et al. 2006). Similarly, resource abundance is positively correlated with dispersal for a broad array of organisms (Zack \& Ligon 1985; Stacey \& Ligon 1991; Komdeur 1992; Putland \& Goldizen 2001; Funston et al. 2003).

Among the social sciurids, a resource-based polygynous mating system is common, leading to matrilines forming the core social unit. In accordance with Greenwood's (1980) predictions for polygynous mating systems, dispersal is often sex-biased, with females remaining in the natal territory and males dispersing more readily [Columbian ground squirrels (Spermophilus columbianus): Wiggett \& Boag 1992; yellowbellied marmots (Marmota flaviventris): Armitage 1981, 1991, 1998, 1999; Van Vuren \& Armitage 1994; Belding's ground squirrels (Spermophilus beldingi): Holekamp 1984; Townsend's ground squirrels (Spermophilus townsendii): Wiggett \& Boag 1993; black-tailed prairie dogs (Cynomys ludovicianus): Hoogland 1995]. Similarly, among communal nesting or cooperative breeding social and semifossorial rodents kin-structured groups are common (Reeve et al. 1990; Lacey \& Wieczorek 2004; Ebensperger et al. 2004).

Whereas Gunnison's prairie dog (Cynomys gunnisoni) males have often been characterized as pursuing a female-based defense strategy (Fitzgerald \& Lechleitner 1974; Rayor 1988; Hoogland 1999), recent empirical and experimental evidence suggests the social system is not driven by male mating strategies 
(Verdolin 2007, 2008). Like many other ground-dwelling sciurids, Gunnison's prairie dogs are large, diurnal, and highly social. Within each colony, individuals have home ranges within territories that persist in space and time (Slobodchikoff 1984; Rayor 1988; Travis \& Slobodchikoff 1993; Verdolin 2007). Males and females communally defend territories over the entire active season and dispersal occurs by both sexes (Rayor 1988; Robinson 1989; Verdolin 2007).

Gunnison's prairie dog populations show variation in their group size and composition among territories, including single male-single female, single male-multiple female, single female-multiple male and multiple male-multiple female groups. This variation is associated with resource abundance and distribution (Slobodchikoff 1984; Travis \& Slobodchikoff 1993; Travis et al. 1995). Within territories, spatial overlap of individuals varies and is correlated with the distribution of resources (Verdolin 2007). A lack of sexual dimorphism and high levels of multiple paternity, regardless of group size and sex ratio on a territory, suggests that resource abundance, not mating strategies, drives social patterns observed in this species (Travis \& Slobodchikoff 1993; Travis et al.1995, 1996; Haynie et al. 2003; Verdolin 2007). Therefore, it remains unclear what role, if any, kinship plays in the formation and stability of Gunnison's prairie dog social groups.

The purpose of this study was to characterize relatedness among members of a social group and determine whether natal philopatry is a significant feature of sociality in this species. Here, natal philopatry refers to remaining in the natal territory. Specifically, we predicted that, if males and females are both dispersing from the natal territory, relatedness among females and among males within a group will not be significantly higher than if groups are formed at random. In contrast, if relatedness among group members is higher within groups than expected if groups formed randomly, we predicted that there would be a positive correlation between relatedness and group size, assuming group size conflicts of interest are more likely to occur among unrelated individuals (Vehencamp 1983). Of particular interest was determining if patterns of kinship among groups varied with resource availability territory size, or population density. Whether or not dispersal in this species is influenced by conflicts over resource availability, we predicted that there would be a positive correlation between resource abundance and relatedness. Lastly, we wanted to determine whether variability in spatial overlap among individuals within territories was correlated with relatedness.

\section{Methods}

\section{Study Area}

Two colonies of Gunnison's prairie dogs were studied within the city limits of Flagstaff, Arizona from May 2003 to Aug. 2005. The first study site, Humane Society (HS), was established in May 2003. The second study site, Country Club (CC) was established in Aug. 2003 (see Verdolin 2007 for details). Experimental manipulations of resource abundance and distribution were conducted from Jun. 1, 2004 to Aug. 1, 2004 and Apr. 1, 2005-May 6, 2005. For each plot, at both HS and CC, a $100 \times 100 \mathrm{~m}$ letter/number grid system consisting of $10010 \times 10 \mathrm{~m}$ quadrats were established using surveyor stakes. Genetic and behavioral data of individuals and habitat data included in this study are from 2004, prior to the onset of experimental manipulations.

\section{Behavior, Vegetation and Territory Observations}

We assigned individuals to social groups and determined group territory boundaries using data on animal locations collected during live-trapping, focal animal behavioral observations, and scan samples as described in Verdolin (2007). Briefly, prairie dogs were live-trapped with Tomahawk live traps (50 $\times 18 \times$ $18 \mathrm{~cm}$ and $48 \times 15 \times 15 \mathrm{~cm}$ ), baited with sunflower seeds. Locations were recorded during focal and scan 
samples based on the proximity (to the nearest $0.5 \mathrm{~m}$ ) of an individual to either a surveyor stake or a flagged burrow and matched with corresponding coordinates obtained with a Garmin ${ }^{\circ}$ Etrex Global Positioning System (Olathe, KS, USA). The term social group refers to individuals that are mutually tolerant of each other, as indicated by behaviors such as greet-kisses (King 1955) and co-feeding, while territory refers to the area occupied and defended by members of a single social group. Animals that were consistently chased out of an area were considered as not belonging to that territory. Individuals that were trapped once and not seen throughout the study were not included as members of any social group.

The abundance and distribution of food plants was obtained by monthly sampling of all plots from Apr. to Aug. each year. A detailed description of methods used for assessing percent cover and estimating aboveground biomass is provided in Verdolin (2007). Briefly, percent cover was estimated for all plots, and all territories within each plot, from digital images using Optimas 3.0 (Optimas Corporation, Meyer Instruments Inc., Houston, TX, USA). Available aboveground biomass for each plot was estimated using the average dry weight of $100 \mathrm{~cm}^{2}$ food plant samples collected from fifteen randomly selected $100 \mathrm{~m}^{2}$ quadrats. Territory food patchiness was calculated as the variance to mean ratio of biomass $/ \mathrm{m}^{2}$. Because food supplementation experiments were conducted beginning in Jun. 2004, all analyses reflect group size and composition and territory and home range sizes in 2004 prior to the onset of the experiments.

All home ranges and territory areas were calculated using the fixed kernel density estimator. Home range was defined as the area routinely used by an individual within a group, while the territory was defined as the area occupied by all members of a particular group. All home ranges and territory areas were estimated using the fixed kernel density estimator (ArcView 3.2a; ESRI 2000, Redlands, CA, USA). When using the fixed kernel approach with a level of smoothing selected by least squares cross-validation, results are less biased and more appropriate for non-normal distributions (Worton 1995; Seaman \& Powell 1996). As opposed to the adaptive kernel, the fixed kernel approach is more stable for

probability contours exceeding $80 \%$. Seaman et al. (1999) suggest that contours greater than $85 \%$ do not provide meaningful biological information and are less reliable. Therefore, we used only the $85 \%$ contour probabilities for all individual home ranges, territory areas, spatial overlap of individual home ranges, and all statistical comparisons (See Verdolin 2007 for details). The proportion of the total home range that any one target individual overlapped with another individual was calculated by taking the area overlapped divided by the home range of the target individual. Proportions were arcsine transformed for analysis.

\section{DNA Extraction and PCR Amplification}

DNA was extracted from hair samples, collected during trapping, using Qiagen DNeasy tissue extraction kits (Qiagen, Inc., Valencia, CA, USA) utilizing a modified protocol for hair provided by the manufacturer. We extracted DNA two independent times following the recommended multiple tubes approach (Taberlet et al. 1996, 1999). Six microsatellite markers were used to determine allelic diversity and heterozygosities. The markers used were CGS-08, CGS-14, CGS-12, CGS-22, CGS-25, and CGS-26 (Stevens et al. 1997; Haynie et al. 2003). Haynie et al. (2003) redesigned markers CGS-8, CGS-12, CGS14, and CGS-22 that were originally published by Stevens et al. (1997). Marker CGS-25 and CGS-26 were used as originally published by Stevens et al. (1997). PCR amplification of the loci was performed using a 20- $\mu \mathrm{l}$ volume that contained: $5 \mu \mathrm{l}$ of extracted genomic DNA, $2 \mu \mathrm{l}$ of Taq buffer, $0.8-\mu \mathrm{l} 50 \mathrm{~mm}$ $\mathrm{MgCl}_{2}, 0.4-\mu \mathrm{l}$ of dNTP, $0.04-\mu \mathrm{l}$ of Taq DNA polymerase, $1 \mu \mathrm{l}$ of 5 ' fluorescent-labeled primer, $5 \mu \mathrm{l}$ of $0.05 \mu / \mu \mathrm{l} \mathrm{BSA}$, and $4.76 \mu \mathrm{l}$ of water. Samples were submitted to the Genomic Analysis and Technology Core facility at the University of Arizona where multiplexed PCR reactions amplified with compatible labeled primers were scored with the $A B I$ PRISM® 3730 DNA Analyzer. Data were visualized using GeneScan freeware (CRIBI GRUP, Padova, Italy). 


\section{Statistical Analysis}

FSTAT 2.9.3 (Goudet 1995) was used to calculate expected heterozygosity, the observed heterozygosity, to test for deviations from Hardy-Weinberg, calculation of FST and FIS values, and detect linkage disequilibrium for each locus using all individuals sampled in 2004 (adult, yearling and juvenile). Pairwise relatedness values were estimated using kinship (Queller \& Goodnight 1989). In kinship (Goodnight Software) the allele sharing coefficient, $r$, is the proportion of alleles shared by two individuals weighted by the frequency of the alleles in the population, thus providing a maximum - likelihood measure of relatedness. Pairwise values of $r$ range from -1 to 1 , with negative values signifying that individuals share, on average, fewer alleles than randomly chosen individuals in the population.

In multiple pairwise comparisons there is a lack of independence among samples because one individual can occur in more than one comparison. Therefore randomization tests were performed using Resampling Stats (Blank et al. 1999) to determine significance. For each group, comparisons among males, among females, and between males and females within and between groups were performed using two randomization procedures. First, the observed mean relatedness within a group was compared with groups that had been randomly reshuffled keeping the same number of pairwise comparisons in each group. This procedure generated a randomized distribution by repeatedly reshuffling the data 10000 times. Second, the mean relatedness value of individuals within a group was compared to the mean relatedness values of individuals in different groups. Observed values of $r$ were randomly reassigned into the two groups 10000 times and the observed difference between the two was compared to the randomized difference. In both tests, the proportion of the resulting values that were as large, or larger, than the observed value determined the $p$-value, with significance for each group determined by using a Bonferroni corrected p-value and Fisher's combined probabilities test. Data for each plot were analyzed separately. We calculated $95 \% \mathrm{Cl}$ for estimates of mean pairwise relatedness by resampling with replacement 10000 times to generate a distribution for which the upper $2.5 \%$ and lower $97.5 \%$ represent the upper and lower confidence intervals (Blank et al. 1999). Outcomes were consistent for all plots using both methods of analyses, so only results from the first procedure are presented here.

We used linear regression to determine if log territory size, density, food biomass, or food dispersion (patchiness) was correlated with group $r$ values among females (groups with $<1$ female), among males (groups with <1 male), and between males and females. We ran a Poisson regression using the generalized linear model to determine whether the number of individuals in a given sex class within a group was correlated with the mean $r$ value for that respective sex class.

Because the proportion of spatial overlap among individuals within groups was variable (among females: $0.30 \pm 0.27$; among males: $0.25 \pm 0.21$ ), a comparison of home range overlap and relatedness was made. For each social group we generated a matrix of pairwise proportion of home range overlap and pairwise $r$ values for comparison among females and among males. A Mantel test was performed for each group and Fisher's combined probabilities test was used to determine significance. Linear regressions were analyzed with JMP 4.0 (SAS Institute, Cary, NC, USA), Poisson regressions were analyzed in Statistica, and the Mantel test was performed using XLSTAT 2007 (ADDINSOFT, NY, USA).

\section{Results}

In these populations, the numbers of unique alleles for each of the six loci ranged from three to nine per locus (Table 1). Observed heterozygosities of all individuals did not deviate significantly from HardyWeinberg for any loci in all populations. In addition, there was no evidence of linkage disequilibrium among the loci. Group $r$ values across the four plots were variable, ranging from -0.44 to +0.50 among males $(S D= \pm 0.24),-0.26$ to $+0.37(S D= \pm 0.18)$ among females, and -0.28 to $+0.24(S D= \pm 0.14)$ 
between males and females. To evaluate kinship, we used data from 134 successfully genotyped adults and yearlings out of a total 137 . Table 2 provides a summary of adult and yearling social groups found on each plot.

Table 1: Number of alleles (A) and expected (HE) and observed (HO) heterozygosity at each locus for adult, yearling and juvenile prairie dogs sampled from each of the four plots: $\mathrm{CCI}(n=133) \mathrm{CCII}(n=70), \mathrm{HSI}(n=$ 131), HSII ( $n=123)$

\begin{tabular}{|c|c|c|c|c|c|c|}
\hline Plot & Locus & A & $\mathrm{H}_{\mathrm{E}}$ & $\mathrm{Ho}_{\mathrm{o}}$ & $F$ & $\theta$ \\
\hline \multirow[t]{6}{*}{$\mathrm{CCl}$} & CGS8 & 6 & 0.73 & 0.76 & -0.024 & 0.005 \\
\hline & CGS12 & 5 & 0.52 & 0.62 & & \\
\hline & CGS14 & 7 & 0.72 & 0.65 & & \\
\hline & CGS22 & 4 & 0.74 & 0.69 & & \\
\hline & CGS25 & 5 & 0.56 & 0.55 & & \\
\hline & CGS26 & 4 & 0.62 & 0.53 & & \\
\hline \multirow[t]{6}{*}{ CCII } & CGS8 & 6 & 0.69 & 0.72 & -0.018 & 0.002 \\
\hline & CGS12 & 9 & 0.77 & 0.74 & & \\
\hline & CGS14 & 5 & 0.75 & 0.68 & & \\
\hline & CGS22 & 4 & 0.77 & 0.69 & & \\
\hline & CGS25 & 5 & 0.49 & 0.48 & & \\
\hline & CGS26 & 4 & 0.63 & 0.65 & & \\
\hline \multirow[t]{6}{*}{$\mathrm{HSI}$} & CGS8 & 6 & 0.73 & 0.67 & -0.047 & 0.031 \\
\hline & CGS12 & 5 & 0.41 & 0.44 & & \\
\hline & CGS14 & 6 & 0.71 & 0.62 & & \\
\hline & CGS22 & 3 & 0.50 & 0.57 & & \\
\hline & CGS25 & 4 & 0.62 & 0.63 & & \\
\hline & CGS26 & 4 & 0.53 & 0.60 & & \\
\hline \multirow[t]{6}{*}{ HSII } & CGS8 & 6 & 0.73 & 0.67 & -0.012 & 0.017 \\
\hline & CGS12 & 5 & 0.41 & 0.44 & & \\
\hline & CGS14 & 5 & 0.71 & 0.62 & & \\
\hline & CGS22 & 4 & 0.50 & 0.57 & & \\
\hline & CGS25 & 4 & 0.62 & 0.63 & & \\
\hline & CGS26 & 4 & 0.53 & 0.60 & & \\
\hline
\end{tabular}

f and $\theta$ are reported across all loci, where $\mathrm{f}$ is equivalent to $\mathrm{F}_{\mathrm{IS}}$ and $\mathrm{h}$ is equivalent to $\mathrm{F}_{\mathrm{ST}}$

\section{Female-Female Relatedness}

We compared the mean relatedness of females within groups with the mean relatedness of females that had been randomly reshuffled into groups keeping the same number of pairwise comparisons in each group. Using the randomization test, we found that the mean relatedness among females within groups did not differ significantly from that of females randomly assigned to groups for all groups (Table 3) and results from the Fisher's combined probability test concurred with results using Bonferroni corrected $p$-values $\left(x^{2}{ }_{0.05[36]}=21.06, p=0.98\right)$. Among females there was no correlation between mean female relatedness per territory and any of the territory-level variables measured in this study (Log territory size: $r^{2}=0.00006, F_{1,18}=0.001, p=0.97,95 \% C L=-0.45$ to +0.45 ; Biomass $/ m^{2}: r^{2}=0.07, F_{1,18}=1.24, p=$ $0.28,95 \% \mathrm{CL}=-0.44$ to +0.47 ; Food patchiness: $r^{2}=0.0006, F_{1,18}=0.11, p=0.75,95 \% C L=-0.45$ to 
+0.45; Density of individuals $/ \mathrm{m}^{2}: \mathrm{r}^{2}=0.002, \mathrm{~F}_{1,18}=0.04, \mathrm{p}=0.84,95 \% \mathrm{CL}=-0.45$ to +0.45 ). In addition, the relationship between relatedness and proportion of home range overlapped of females was not statistically significant $\left(x_{0.05[22]}^{2}=24.02, p=0.35\right)$. Lastly, the number of females within a group was not correlated with female relatedness for that group (GdLM: Wald statistic $=1.90, n=19, p=0.17$ ).

Table 2: Summary of adult and yearling social groups found on each plot, including group size, and male to female sex-ratio (M:F) prior to experimental treatments in 2004

\begin{tabular}{|lccc|}
\hline Plot & Group & Group Size & M:F \\
\hline $\mathrm{CCl}$ & 1 & 10 & $1: 1$ \\
$\mathrm{CCl}$ & 2 & 8 & $0.33: 1$ \\
$\mathrm{CCl}$ & 3 & 12 & $0.71: 1$ \\
$\mathrm{CCl}$ & 4 & 5 & $0.66: 1$ \\
$\mathrm{CCl}$ & 5 & 7 & $0.4: 1$ \\
$\mathrm{CCl}$ & 6 & 7 & $0.75: 1$ \\
$\mathrm{CCII}$ & 1 & 5 & $0.25: 1$ \\
$\mathrm{CCII}$ & 9 & $0.28: 1$ \\
$\mathrm{CCII}$ & 2 & 6 & $1: 1$ \\
$\mathrm{CCII}$ & 3 & 3 & $0.5: 1$ \\
$\mathrm{HSI}$ & 4 & 9 & $0.5: 1$ \\
$\mathrm{HIS}$ & 1 & 3 & $2: 1$ \\
$\mathrm{HIS}$ & 2 & 7 & $0.75: 1$ \\
$\mathrm{HIS}$ & 3 & 4 & $1: 1$ \\
$\mathrm{HIS}$ & 4 & 5 & $0.66: 1$ \\
$\mathrm{HSII}$ & 5 & 4 & $0.33: 1$ \\
$\mathrm{HSII}$ & 7 & $0.75: 1$ \\
$\mathrm{HSII}$ & & 8 & $0.6: 1$ \\
$\mathrm{HSII}$ & 1 & 14 & $1: 1$ \\
$\mathrm{HSII}$ & 2 & 4 & $1: 1$ \\
\hline
\end{tabular}

CC, Country Club, HS, Humane Society.

\section{Male-Male Relatedness}

As with females, the mean relatedness of males within groups was compared with the mean relatedness of males that had been randomly reshuffled into groups keeping the same number of pairwise comparisons in each group. Using the randomization test, we found that mean relatedness among males within groups did not differ significantly from that of males randomly assigned to groups (Table 3) and results from the Fisher's combined probability test concurred with the findings using Bonferroni corrected $p$-values $\left(x_{0.05[26]}^{2}=11.12, p=0.99\right)$. Similar to the results for females, there was no correlation between mean male relatedness per territory and any of the territory-level variables measured in this study (Log territory size: $\mathrm{r}^{2}=0.11, \mathrm{~F}_{1,16}=0.19, \mathrm{p}=0.19,95 \% \mathrm{CL}=-0.44$ to +0.49 ; Biomass $/ \mathrm{m}^{2}: \mathrm{r}^{2}=0.02, \mathrm{~F}_{1,18}=$ $0.43, p=0.52,95 \% \mathrm{CL}=-0.46$ to +0.47 ; Food patchiness: $r^{2}=0.008, F_{1,16}=0.12, p=0.73,95 \% \mathrm{CL}=$ 0.47 to +0.47 ; Density of individuals $/ \mathrm{m}^{2}: \mathrm{r}^{2}=0.02, \mathrm{~F}_{1,16}=0.46, \mathrm{p}=0.51,95 \% \mathrm{CL}=-0.46$ to +0.47 ). The relationship between relatedness and proportion of home range overlapped among males was not statistically significant $\left(x_{0.5[22]}^{2}=29.84, p=0.12\right)$. Lastly, male relatedness within groups was not correlated with the number of males present in that group (GdLM: Wald statistic $=0.07, n=17, p=0.79$ ). 
Table 3: The mean relatedness, $r$, value with bootstrap confidence intervals $(\mathrm{Cl})$ for each group among females (F-F), among males (M-M) and between males and females (M-F) with $95 \% \mathrm{Cl}$

\begin{tabular}{|lcccc|}
\hline Plot & Group & F-F & M-M & F-M \\
\hline CCI & 1 & $0.006(-0.12$ to 0.14$)$ & $0.14(-0.14$ to 0.43$)$ & $0.07(-0.08$ to 0.21$)$ \\
& 2 & $0.04(-0.12$ to 0.19$)$ & $0.03(-0.10$ to 0.17$)$ & $0.06(-0.06$ to 0.19$)$ \\
& 3 & $0.15(-0.03$ to 0.26$)$ & $0.03(-0.20$ to 0.21$)$ & $-0.21(-0.11$ to 0.31$)$ \\
& 4 & $0.02(-0.06$ to 0.10$)$ & - - $^{-}$ & $-0.07(-0.28$ to 0.12$)$ \\
& 5 & $-0.05(-0.16$ to 0.07$)$ & $0.06(-0.05$ to 0.18$)$ & $-0.02(-0.09$ to 0.13$)$ \\
CCII & 6 & $0.04(-0.18$ to 0.25$)$ & $0.02(-0.12$ to 0.15$)$ & $-0.07(-0.15$ to 0.02$)$ \\
& 1 & $-0.13(-0.22$ to $(-) 0.03)$ & $0.005(-0.34$ to 0.56$)$ & $-0.07(-0.15$ to 0.01$)$ \\
& 2 & $0.014(-0.05$ to 0.14$)$ & $0.15(-0.09$ to 0.48$)$ & $0.01(-0.07$ to 0.10$)$ \\
HSI & 3 & $0.13(-0.07$ to 0.34$)$ & $0.002(-0.26$ to 0.37$)$ & $0.02(-0.07$ to 0.11$)$ \\
& 4 & -- & -- & $0.24(-0.05$ to 0.67$)$ \\
& 1 & $-0.05(-0.17$ to 0.08$)$ & $-0.23(-0.44$ to 0.17$)$ & $-0.06(-0.19$ to 0.08$)$ \\
& 2 & -- & -- & $-0.008(-0.16$ to 0.15$)$ \\
HSII & 3 & $0.38(0.24$ to 0.45$)$ & $-0.01(-0.11$ to 0.09$)$ & $0.18(0.03$ to 0.33$)$ \\
& 4 & -- & -- & $-0.27(-0.42$ to $(-) 0.04)$ \\
& 5 & $0.32(0.10$ to 0.45$)$ & -- & $-0.06(-0.29$ to 0.19$)$ \\
& 1 & $-0.26(-0.39$ to $(-) 0.06)$ & -- & $0.14(-0.05$ to 0.32$)$ \\
& 2 & $0.28(-0.02$ to 0.75$)$ & $-0.07(-0.26$ to 0.04$)$ & $-0.11(-0.27$ to 0.13$)$ \\
& 3 & $0.09(-0.07$ to 0.26$)$ & $0.28(0.05$ to 0.47$)$ & $0.02(-0.12$ to 0.18$)$ \\
& 4 & $0.08(-0.03$ to 0.19$)$ & $-0.18(-0.41$ to 0.03$)$ & $-0.01(-0.12$ to 0.09$)$ \\
& 5 & -- & -- & $-0.14(-0.27$ to $(-) 0.05)$ \\
\hline
\end{tabular}

${ }^{\mathrm{a}}$ Groups where there were $\leq 2$ individuals available.

Male-Female Relatedness

The final comparison examined the pairwise relatedness of males and females. The same procedure explained above was performed. We found that mean relatedness among males and females within groups did not differ significantly from that of randomly assigned individuals (Table 3 ) and results from the Fisher's combined probability test concurred with the findings using Bonferroni corrected $p$-values $\left(x^{2}{ }_{0.05[40]}=19.48, p=0.99\right)$. As with male-male and female-female comparisons, there was no correlation between mean male-female relatedness per territory and any of the territory-level variables measured in this study (Log territory size: $r^{2}=0.06, F_{1,19}=1.11, p=0.30,95 \% C L=-0.43$ to +0.45 ; Biomass $/ \mathrm{m}^{2}: \mathrm{r}^{2}=0.03, \mathrm{~F}_{1,18}=0.51, \mathrm{p}=0.48,95 \% \mathrm{CL}=-0.44$ to +0.45 ; Food patchiness: $\mathrm{r}^{2}=0.02, \mathrm{~F}_{1,19}=$ $0.44, p=0.51,95 \% C L=-0.44$ to +0.45 ; Density of individuals $/ \mathrm{m}^{2} \mathrm{r}^{2}=0.09, \mathrm{~F}_{1,19}=1.76, \mathrm{p}=0.20,95 \%$ $C L=-0.42$ to +0.46$)$.

\section{Discussion}

The results of this study suggest that kin selection is not maintaining Gunnison's prairie dog social groups or influencing spatial structure within groups. These results differ markedly from observational studies of Gunnison's prairie dogs in other areas. Although some individuals within groups were more closely related to each other, no group had relatedness values that differed significantly from random, and none of the variables measured in this study appeared to play a significant role in explaining patterns of relatedness among females or males. In addition, there was no indication that males and females differed 
in their patterns of relatedness within groups, suggesting that sex-biased dispersal was not occurring in these populations. Lastly, results indicate that relatedness has little bearing on the spatial structure among males and among females within groups.

These results contrast with those from other ground-dwelling sciurids and other communally nesting rodents (Armitage 1981, 1991, 1998, 1999; Holekamp 1984; Holekamp \& Sherman 1989; Wiggett \& Boag 1992, 1993; Hoogland 1995; Lacey \& Wieczorek 2004; Ebensperger et al. 2004). Preliminary genetic analysis from Travis et al. (1996) appeared to support male-biased dispersal and female philopatry in Gunnison's prairie dogs reported in an observational study by Hoogland (1999). However, in our analysis, six microsatellite loci were used for comparison, whereas three minisatellite loci were utilized by Travis et al. (1996). The different methodology and subsequent statistical analyses make it difficult to directly compare our findings with those presented by Travis et al. (1996) and may explain the different conclusions. It is also possible that the difference in outcome reflects the variability in social structure and dispersal patterns that has frequently been observed within and between colonies of Gunnison's prairie dogs (Slobodchikoff 1984; Robinson 1989; Travis \& Slobodchikoff 1993; Travis et al. 1995; Verdolin 2007).

For example, in contrast to Hoogland's (1999) finding of male-biased dispersal, Robinson (1989) concluded that both males and females dispersed, but that males more frequently dispersed greater distances. If both males and females disperse, one might not expect kin structure to be present among females. In our study, although some individuals within groups were related, females belonging to the same group were rarely closely related and patterns of relatedness did not differ between the sexes, suggesting female and male dispersal patterns in these populations may be similar to those reported by Robinson (1989).

Why would both sexes disperse in these populations of Gunnison's prairie dogs? According to Greenwood (1980), if dispersal is linked to mating systems, then the sex that competes over resources should be philopatric. Gunnison's prairie dog males have been described as pursuing a harem polygynous strategy (Hoogland 1999), in which case, the expectation is that females should be philopatric and therefore closely related. However, there is an evidence that indicates males in these populations are not pursuing such a mating strategy, and perhaps not even a resource defense strategy. For instance, there is a lack of sexual dimorphism between males and females, both males and females communally defended territory boundaries without bias, territory size is correlated with the number of males and females, there is no significant difference between male and female home ranges within territories, and females range further than males during the mating season (Verdolin 2007). Thus, if male Gunnison's prairie dogs in this population are not using a female-defense mating strategy, there may be little benefit to being philopatric.

If dispersal is not linked to the individual mating strategies and there is no sex-biased dispersal in Gunnison's prairie dogs (Robinson 1989), what other factors might predict who disperses and when? Experimental studies have suggested that dispersal may be more tightly linked to population density and resource availability (Emlen 1982, 1995; Koenig et al. 1992; Johnson et al. 2002). If food abundance plays a role in Gunnison's prairie dog dispersal, one would expect that as food availability increased, relatedness would correspondingly increase, due to greater retention of offspring. In this study, we found there was no relationship between relatedness and food abundance or food dispersion, and that neither population density nor territory size was correlated with relatedness.

Despite failing to detect kin structure within groups for either sex, the variation in spatial overlap among individuals within groups could reflect a greater tolerance to closely related individuals. However, it 
appears that relatedness may not be important in determining spacing behavior of males and females within territories.

The lack of relatedness in this study could arise if insufficient genetic markers were used to detect relatedness among individuals. Recently Van Horn et al. (2008) addressed the accuracy of kinship estimates when not incorporating pedigree information and suggested that relatedness estimates may be misleading. While it is possible that our results underestimate kinship, Van Horne et al. (2008) report that the majority of errors favored misassigning individuals to a higher class of relatedness. As a result, if we used an insufficient number of markers, we would be more likely to conclude that individuals are more closely related than in fact they actually are. Furthermore, inspection of the $95 \%$ confidence intervals for mean female-female relatedness in individual groups in this study (Table 3) shows that in some plots, the existing sample size of microsatellite loci and females per group was sufficient to constrain mean relatedness estimates relatively close to 0 (e.g., in four of six groups in $\mathrm{CCl}$, the upper confidence limit of mean relatedness was 0.19 or less, implying that the true mean relatedness value was $97.5 \%$ certain to be less than this value).

If neither mate defense nor food competition are obvious explanations, why else might both males and females disperse from their birth territories in this population? The lack of relatedness among individuals in groups could reflect stochastic demographic variation in survivorship. If more females survive, there may be greater competition among females for space and resources, leading some females to choose to disperse in search of better territories. However, neither territory size, density nor food abundance and dispersion appear to play a significant role in patterns of relatedness among females, suggesting that female competition over resources is an insufficient explanation. In addition, previous research indicates that there is little difference in the survivorship of male and female offspring (Hoogland 2001).

Another possibility for why females disperse may be related to gaining access to suitable nesting burrows. Data from this study are inadequate to ascertain whether certain burrows are consistently used as maternity burrows from year to year, but if there are features that constitute a suitable nesting burrow, and there is some limitation to how many burrows are available, competition for maternity burrows may place an upper limit on the number of yearling females that can remain on their natal territory. Communal nesting and kin-structured groups has been documented in several species of semifossorial rodents and potentially black-tailed prairie dogs (Dobson et al. 1998; Reeve et al. 1990; Lacey \& Wieczorek 2004; Ebensperger et al. 2004). Although female Gunnison's prairie dogs have been occasionally observed nesting communally in other areas (Haynie et al. 2003), they were rarely seen doing so in these populations, potentially increasing competition for maternity burrows. While individuals of both sexes were seen utilizing common burrows, patterns of spatial overlap and relatedness from this study suggest that kinship does not predict burrow sharing.

One possible resource necessary for both males and females is access to hibernation burrows. Unlike black-tailed prairie dogs, Gunnison's are obligate hibernators, although hibernation is interrupted by cyclic periods of activity (Bakko \& Nahorniak 1986). Burrow excavations clearly show that not all burrow structures have bedding or nesting material present (Smith 1982; Verdolin et al. 2008), but whether only particular burrows are suitable for hibernation remains unclear. Previous studies indicate that the deepest parts of burrows are more thermally stable and that hibernacula must be constructed at precise depths in order to avoid overwinter freezing (Smith 1982). The topography of certain areas may limit the number of suitable locations to construct hibernacula, and although laboratory prairie dogs have been observed sleeping together (Smith 1982), it is not clear whether individuals hibernate together. Thus, hibernacula may be a key limiting resource for both males and females. 
The results of this study indicate that kin selection, for both males and females, may be unimportant to forming and maintaining social groups in these populations. Furthermore, relatedness does not appear to influence the spatial interaction of individuals within the same group. Given that kin selection can be rejected as the basis of maintaining sociality in this species, why are Gunnison's prairie dogs territorial and social? Because larger groups attain a higher per capita access to food while simultaneously reducing individual defense costs (Verdolin 2007), we propose that sociality in this species may be the result of a more generalized mutualism such as group augmentation.

\section{Acknowledgements}

We are grateful to Dr Charles Janson, for his guidance and invaluable contribution to this manuscript. We would also like to thank Drs Kenneth Armitage, John True and Patricia Wright, whose comments and suggestions greatly improved this manuscript. For unbelievable field support, veterinary services, and friendship, a heartfelt thank you to Dr David Washabau. This project could not have been completed without many people dedicating their time and effort in the field, including Bill and Theresa Emig, Carolyn Parker, Perry Crompton, Kristen Hoss, Jessica Hagan and many others. For help in the lab we would like to thank undergraduates Ariba Hashmi and Sana Hashmi. This study was supported by grants from the American Museum of Natural History, Sigma Xi and the American Society of Mammalogists. Generous donations of microchips were made by Schlering-Plough and sunflower seeds were kindly provided by Western Organics, Inc. For charitably allowing use of tomahawk traps we thank Norris Dodd. Vegetation data were analyzed in the FERTL Lab housed in the Department of Ecology and Evolution, Stony Brook University. Lastly, we thank the City of Flagstaff, Arizona Game and Fish Department and the Arizona State Land Trust Department for all necessary permits. This project was approved by Stony Brook University Animal Care and Use Committee (Permit \#1290).

\section{Literature Cited}

Alexander, R. 1974: The evolution of social behavior. Annu. Rev. Ecol. Syst. 5, 325-383.

Armitage, K. B. 1981: Sociality as a life-history tactic of ground squirrels. Oecologia 48, 36-49.

Armitage, K. B. 1991: Social and population-dynamics of yellow-bellied marmots - results from long-term research. Annu. Rev. Ecol. Syst. 22, 379-407.

Armitage, K. B. 1998: Reproductive strategies of yellowbellied marmots: energy conservation and differences between the sexes. J. Mammal. 79, 385-393.

Armitage, K. B. 1999: Evolution of sociality in marmots. J. Mammal. 80, 1-10.

Armitage, K. B. 2003: Reproductive competition in female yellow-bellied marmots. Compétition reproductive chez les marmottes femelles à ventre jaune. In: Adaptive Strategies and Diversity in Marmots / Stratégies Adaptatives et Diversité Chez les Marmottes (Ramousse, R., Allainé, D. \& Le Berre, M., Eds). International Network on Marmots, Lyon, France, pp. 133-142.

Baglione, V., Canestrari, D., Marcos, J. M. \& Ekman, J. 2006: Experimentally increased food resources in the natal territory promote offspring philopatry and helping in cooperatively breeding carrion crows. Proc. R. Soc. Lond., B 273, 1529-1535.

Bakko, E. \& Nahorniak, J. 1986: Torpor patterns in captive white-tailed prairie dogs (Cynomys leucurus). J. Mammal. 67, 576-578.

Betram, B. 1978: Living in groups: predators and prey. In: Behavioral Ecology, 1st edn (Krebs, J. R. \& Davies, N. B., Eds). Blackwell Scientific Publications, London, pp. 64-96.

Blank, S., Setter, C. \& Bruce, P. 1999: Resampling Stats in Excel. Resampling Stats, Inc., Arlington, VA.

Brown, G. E. \& Brown, J. A. 1993: Social dynamics in salmonid fishes: do kin make better neighbors? Anim. Behav. 45, 863-871. 
Clutton-Brock, T. H. 2002: Breeding together: kin selection and mutualism in cooperative vertebrates. Science 296, 69-72.

Daniels, S. J. \& Walters, J. R. 2000: Between-year breeding dispersal in Red-cockaded woodpeckers: multiple causes and estimated cost. Ecology 81, 2473-2484.

Dobson, F. S., Chesser, R. K., Hoogland, J. L., Sugg, D. W. \& Foltz, D. W. 1998: Breeding groups and gene dynamics in a socially structured population of prairie dogs. J. Mammal. 79, 671-680.

Dugatkin, L. A. 1997: Cooperation Among Animals: An Evolutionary Perspective. Oxford Univ. Press, New York, NY.

Ebensperger, L., Hutado, M. J., Soto-Gamboa, M., Lacey, E. A. \& Chang, A. T. 2004: Communal nesting and kinship in degus (Octodon degus). Naturwissenschaften 91, 391-395.

Emlen, S. T. 1982: The evolution of helping .1. An ecological constraints model. Am. Nat. 119, 29-39.

Emlen, S. T. 1984: Cooperative breeding in birds and mammals. In: Behavioural Ecology: An Evolutionary Approach, 2nd edn (Krebs, J. R. \& Davies, N. B., Eds). Blackwell Scientific Publications, London, pp. 305-339.

Emlen, S. T. 1995: An evolutionary-theory of the family. Proc. Natl. Acad. Sci. 92, 8092-8099.

Emlen, S. T. 1997: Predicting family dynamics in social vertebrates. In: Behavioural Ecology: An Evolutionary Approach, 4th edn (Krebs, J. R. \& Davies, N. B., Eds). Blackwell Scientific Publications, London, pp. 228-253.

Fitzgerald, J. P. \& Lechleitner, R. R. 1974: Observation on the biology of Gunnison's prairie dog in central Colorado. Am. Midl. Nat. 92, 146-163.

Funston, P. J., Mills, M. G. L., Richardson, P. R. K. \& van Jaarsveld, A. S. 2003: Reduced dispersal and opportunistic territory acquisition in male lions (Panthera leo). J. Zool. 259, 131-142.

Giraldeau, L. \& Caraco, T. 2000: Social foraging theory. In: Monographs in Behavior and Ecology (Krebs, J. R. \& Clutton-Brock, T. H., Eds). Princeton Univ. Press, Princeton, New Jersey, pp. 85-118.

Goudet, J. 1995: FSTAT version 1.2.: a computer program to calculate F-statistics. J. Hered. 86, 485486.

Greenwood, P. J. 1980: Mating systems, philopatry and dispersal in birds and mammals. Anim. Behav. 28, 1140-1162.

Griffin, A. S. \& West, S. A. 2002: Kin selection: fact and fiction. Trends Ecol. Evol. 17, 15-21.

Hamilton, W. D. 1964a: The genetic evolution of social behaviour, I. J. Theor. Biol. 7, 1-16.

Hamilton, W. D. 1964b: The genetic evolution of social behaviour, II. J. Theor. Biol. 7, 17-52.

Hatchwell, B. J. \& Komdeur, J. 2000: Ecological constraints, life history traits and the evolution of cooperative breeding. Anim. Behav. 59, 1079-1086.

Haynie, M. L., Vandenbussche, R. A., Hoogland, J. L. \& Gilbert, D. A. 2003: Parentage, multiple paternity, and breeding success in Gunnison's and Utah prairie dogs. J. Mammal. 84, 1244-1253.

Holekamp, K. E. 1984: Natal Dispersal in belding groundsquirrels (Spermophilus beldingi). Behav. Ecol. Sociobiol. 16, 21-30.

Holekamp, K. E. \& Sherman, P. W. 1989: Why male ground-squirrels disperse. Am. Sci. 77, 232-239.

Hoogland, J. L. 1995: The Black-Tailed Prairie dog: Social Life of a Burrowing Mammal. Univ. of Chicago Press, Chicago, IL.

Hoogland, J. L. 1999: Philopatry, dispersal, and social organization of Gunnison's prairie dogs. J. Mammal. 80, 243-251.

Hoogland, J. L. 2001: Black-tailed, Gunnison's and Utah prairie dogs reproduce slowly. J. Mammal. 82, 917-927.

Janson, C. H. 1988: Intra-specific food competition and primate social-structure - a synthesis. Behaviour 105, 1-17.

Janson, C. H. 1992: Evolutionary ecology of primate social structure. In: Evolutionary Ecology and Human Behavior (Smith, E. A. \& Winterhalder, B., Eds). Aldine de Gruyter, New York, NY, pp. 95-130. 
Johnson, D. D. P., Kays, R., Blackwell, P. G. \& Macdonald, D. W. 2002: Does the resource dispersion hypothesis explain group living? Trends Ecol. Evol. 17, 63-570.

King, J. A. 1955: Social Behavior, Social Organization, and Population Dynamics in a Black-Tailed Prairiedog Town in the Black Hills of South Dakota. PhD Thesis, Univ. of Michigan, Ann Arbor, MI.

Koenig, W. D., Pitelka, F. A., Carmen, W. J., Mumme, R. L. \& Stanback, M. T. 1992: The evolution of delayed dispersal in cooperative breeders. Q. Rev. Biol. 67, 111-150.

Komdeur, J. 1992: Importance of habitat saturation and territory quality for evolution of cooperative breeding in the Seychelles warbler. Nature 358, 493-495.

Lacey, E. A. \& Wieczorek, J. R. 2004: Kinship in colonial tuco-tucos: evidence from group composition and population structure. Behav. Ecol. 15, 988-996.

Putland, D. A. \& Goldizen, A. W. 2001: Family dynasties in the Tasmanian native hen (Gallinula mortierii). Behav. Ecol. Sociobiol. 51, 26-32.

Queller, D. C. \& Goodnight, K. F. 1989: Estimating relatedness using genetic-markers. Evolution 43, 258-275.

Rayor, L. S. 1988: Social organization and space-use in Gunnison's prairie dog. Behav. Ecol. Sociobiol. 22, 69-78.

Reeve, H. K. \& Nonacs, P. 1997: Within-group aggression and the value of group membership: theory and field test with social wasps. Behav. Ecol. 8, 75-82.

Reeve, H. K., Westneat, D. F., Noon, W. A., Sherman, P. W. \& Aquadro, C. F. 1990: DNA fingerprinting reveals high levels of inbreeding in colonies of the eusocial naked mole-rat. Proc. Natl. Acad. Sci. 87, 2496-2500.

Robinson, A. T. 1989: Dispersal of the Gunnison's Prairie dog, Cynomys gunnisoni. Masters Thesis, Northern Arizona Univ., Flagstaff, AZ.

Seaman, D. E. \& Powell, R. A. 1996: An evaluation of the accuracy of kernel density estimators for home range analysis. Ecology 77, 2075-2085.

Seaman, D. E., Millspaugh, J. J., Kernohan, B. J., Brundidge, G. C., Raedke, K. J. \& Gitzen, R. A. 1999: Effects of sample size on kernel home range estimators. J. Wildl. Manage. 63, 739-747.

Shields, W. M. 1982: Philopatry, Inbreeding, and the Evolution of sex. State Univ. of New York Press, Albany, NY.

Slobodchikoff, C. N. 1984: Resources and the evolution of social behavior. In: A new Ecology: Novel Approaches to Interactive Systems (Price, P. W., Slobodchikoff, C. N. \& Gaud, W. S., Eds). John Wiley and Sons, Inc., New York, pp. 227-251.

Slobodchikoff, C. N. \& Schultz, W. C. 1988: Cooperation, aggression, and the evolution of social behavior. In: The Ecology of Social Behavior (Slobodchikoff, C. N., Ed.). Academic Press, Inc., San Diego, pp. 13-32.

Smith, J. L. 1982: Hibernation in the Zuni prairie dog, Cynomys gunnisoni zuniensis. Masters Thesis. Northern Arizona Univ., Flagstaff, AZ.

Solomon, N. G. \& French, J. A. 1997: Cooperative Breeding in Mammals. Cambridge Univ. Press, Cambridge.

Stacey, P. B. \& Ligon, J. D. 1987: Territory quality and dispersal options in the acorn woodpecker, and a challenge to the habitat-saturation model of cooperative breeding. Am. Nat. 130, 654-676.

Stacey, P. B. \& Ligon, J. D. 1991: The benefits-of-philopatry hypothesis for the evolution of cooperative breeding - variation in territory quality and group-size effects. Am. Nat. 137, 831-846.

Stevens, S., Coffin, J. \& Strobeck, C. 1997: Microsatellite loci in Columbian ground squirrels Spermophilus columbianus. Mol. Ecol. 6, 493-495.

Taberlet, P., Griffin, S., Goosens, B., Questiau, S., Manceau, V., Escaravage, V., Waits, L. P. \& Bouvet, J. 1996: Reliable genotyping of samples with very low DNA quantities using PCR. Nucleic Acids Res. 24, 3189-3194. 
Taberlet, P., Waits, L. P. \& Luikart, G. 1999: Noninvasive genetic sampling: look before you leap. Trends Ecol. Evol. 14, 323-327.

Travis, S. E. \& Slobodchikoff, C. N. 1993: Effects of food resource distribution on the social system of Gunnison's prairie dog (Cynomys gunnisoni). Can. J. Zool. 71, 1186-1192.

Travis, S. E., Slobodchikoff, C. N. \& Keim, P. 1995: Ecological and demographic effects on intraspecific variation in the social system of prairie dogs. Ecology 76, 1794-1803.

Travis, S. E., Slobodchikoff, C. N. \& Keim, P. 1996: Social assemblages and mating relationships in prairie dogs: a DNA fingerprint analysis. Behav. Ecol. 7, 95-100.

Van Horn, R. C., Altmann, J. \& Alberts, S. C. 2008: Can't get there from here: inferring kinship from pairwise genetic relatedness. Anim. Behav. 75, 1173-1180.

Van Vuren, D. \& Armitage, K. B. 1994: Survival of dispersing and philopatric yellow-bellied marmots what is the cost of dispersal. Oikos 69, 179-181.

Vehrencamp, S. L. 1983: Optimal degree of skew in cooperative societies. Am. Zool. 23, 327-335.

Verdolin, J. L. 2007: Resources, not male mating strategies, are a determinant of social structure in Gunnison's prairie dogs (Cynomys gunnisoni). Behaviour 144, 1361-1382.

Verdolin, J. L. 2008: Social Structure and Mating System of Gunnison's Prairie dog (Cynomys gunnisoni). Ph.D. Thesis, Stony Brook Univ., Stony Brook, NY.

Verdolin, J. L., Lewis, K. \& Slobochikoff, C. N. 2008: Morphology of prairie dog burrows: a comparison among Gunnison's, black-tailed, white-tailed, and Utah prairie dogs. Southwest. Nat. 53, 201-207.

Waser, P. M. \& Jones, W. T. 1983: Natal philopatry among solitary mammals. Q. Rev. Biol. 58, 355-390.

Wasser, S. K. \& Barash, D. P. 1983: Reproductive suppression among female mammals: implications for biomedicine and sexual selection theory. Q. Rev. Biol. 58, 513-538.

West, S. A., Murray, M. G., Machado, C. A., Griffin, A. S. \& Herre, E. A. 2001: Testing Hamilton's rule with competition between relatives. Nature 409, 510-513.

Wiggett, D. \& Boag, D. A. 1992: The resident fitness hypothesis and dispersal by yearling female Columbian ground-squirrels. Can. J. Zool. 70, 1984-1994.

Wiggett, D. R. \& Boag, D. A. 1993: The proximate causes of male-biased natal emigration in Columbian ground squirrels. Can. J. Zool. 71, 204-218.

Worton, B. 1995: Using Monte Carlo simulations to evaluate kernel-based home range estimators. J. Wildl. Manage. 59, 794-800.

Wrangham, R. W. \& Rubenstein, D. I.. 1986: Ecology and Social Evolution: Birds and Mammals. Princeton Univ. Press, Princeton, NJ.

Zack, S. \& Ligon, J. D. 1985: Cooperative breeding in Lanius shrikes.2. Maintenance of group-living in a nonsaturated habitat. Auk. 102, 766-773. 